\title{
CHANGE OF RESISTANCE WITH TEMPERATURE OF VARIOUS SODIUM AMALGAMS.
}

By Ralph C. Rodgers.

\section{HISTORICAL.}

$\mathrm{T}_{\mathrm{N}}$ the present investigation of the change of resistance of several sodium amalgams with temperature a direct method of measuring the resistance change of the specimen was used by employing the Kelvin double bridge. ${ }^{1}$

A great deal of work has been done on the resistance of mercury and of sodium by various investigators. Among those who have studied the resistance of these metals may be mentioned Matthiessen, ${ }^{2}$ Dewar and Fleming, ${ }^{3}$ Bernini, ${ }^{4}$ Onnes and Clay, ${ }^{5}$ Guntz and Broniewski, ${ }^{6}$ Onnes, ${ }^{7}$ Baltruszajtis, ${ }^{8}$ Onnes and Holst, ${ }^{9}$ Lohr, ${ }^{10}$ Hachspill, ${ }^{11}$ Hornbeck, ${ }^{12}$ and Northrup. ${ }^{13}$

While various properties of the sodium amalgams have been studied by several investigators including Berthelot, ${ }^{14}$ Guntz and Ferée, ${ }^{15}$ Kerp and Böttger, ${ }^{16}$ Maey, ${ }^{17}$ Kurnakow, ${ }^{18}$ Schüller, ${ }^{19}$ and Vanstone, ${ }^{20}$ very

${ }^{1}$ W. Thomson, Phil. Mag., No. 24, I862, p. I49. Leeds and Northrup, Standard Resistances, Pamphlet No. 4 .

${ }^{2}$ Matthiessen, Fortschritte der Physik, Vol. I2, I856, pp. 452-454; Vol. I4, I858, pp. 444-445; Phil. Mag., 4th Series, Vol. I2, I856, p. I99; Vol. I3, I857, pp. 8I-90; Proc. Roy. Soc., Vol. 9, I857, p. 95-I00.

${ }^{3}$ Dewar and Fleming, Proc. Roy. Soc., Vol. 60, p. 76.

${ }^{4}$ Bernini, N. Cimento, Vol. 49, I903, p. 2 I.

${ }^{5}$ Onnes and Clay, Communications from Phys. Lab., Univ. of Leiden, INo. $99 c$.

${ }^{6}$ Guntz and Broniewski, Comptes Rendus, No. 26, December, 1908, pp. I474-I477.

${ }^{7}$ Onnes, K. A. W. Amsterdam, Proc. I4, pp. 8I8-82 I, February 22, I9I2.

${ }^{8}$ Baltruszajtis, Acad. Sci. Cracovie Bull., $9 a$, pp. 888-898.

${ }_{9}^{9}$ Onnes and Holst, K. A. W. Amsterdam, Proc. I7, pp. 508-5I3, I9I4.

${ }^{10}$ Lohr, Science Abstracts, Vol. 8, Abs. No. 587, p. I92.

11 Hachspill, Ann. Chim. Phys., 28, Ser. 8, pp. 613-696, I9I3.

${ }^{12}$ Hornbeck, Phys. Rev., Series 2, pp. 2 I 7-240, September, I9I3.

${ }^{13}$ Northrup, Amer. Electrochem. Soc. Trans., 20, pp. I85-203.

14 Berthelot, Ann. Chim. Phys., I879, Vol. I8, p. 442.

15 Guntz and Ferée, Comptes Rendus, I900, Vol. I3I, p. I82.

${ }^{16}$ Kerp and Böttger, Zeit. Anorg. Chem., rgor, Vol. 25, p. r.

17 Maey, Zeit. Phys. Chem., I899, Vol. 29, p. II9.

18 Kurnakow, Zeit. Anorg. Chem., I90o, Vol. 23, p. 434.

19 Schüller, Zeit. Anorg. Chem., I904, Vol. 40, p. 385.

${ }_{20}$ Vanstone, The Chemical News, Vol. I03, No. 2682, p. I8I; No. 2683 , p. I98; No. 2684 . p. 207 . 
little work has been done on the resistance of the amalgams. Bornemann and Müller, ${ }^{21}$ Bornemann and Rauschenplat, ${ }^{22}$ and Vanstone $^{23}$ have determined the electrical conductivity at fixed temperatures above $0^{\circ} \mathrm{C}$.

\section{Овјест.}

The purpose of the present investigation was to determine the change of resistance of several sodium amalgams with change of temperature from $-185^{\circ} \mathrm{C}$. to $+150^{\circ} \mathrm{C}$., and to study the depression of the freezingpoint of mercury in amalgams of small atomic percentage by the method of the sudden change of resistance of the amalgam due to the change to the solid state. Eight specimens of amalgams were studied by the comparison of their resistance change to that of mercury in the same container throughout the range of temperature.

\section{Apparatus.}

The apparatus used consisted of a container to hold the amalgam, a copper resistance thermometer, a Kelvin bridge to determine the re-

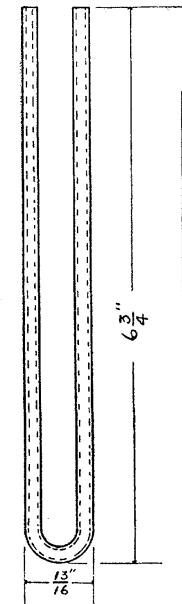

(1)

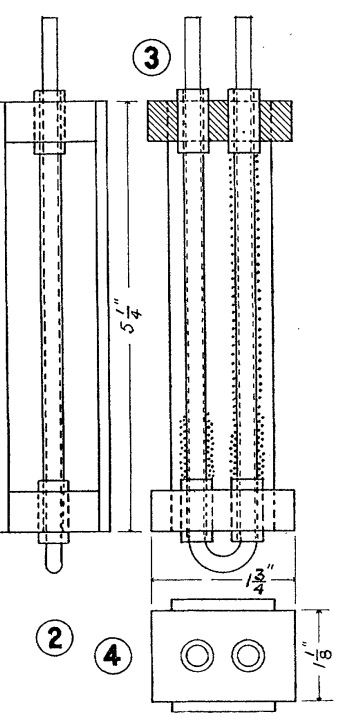

(7)

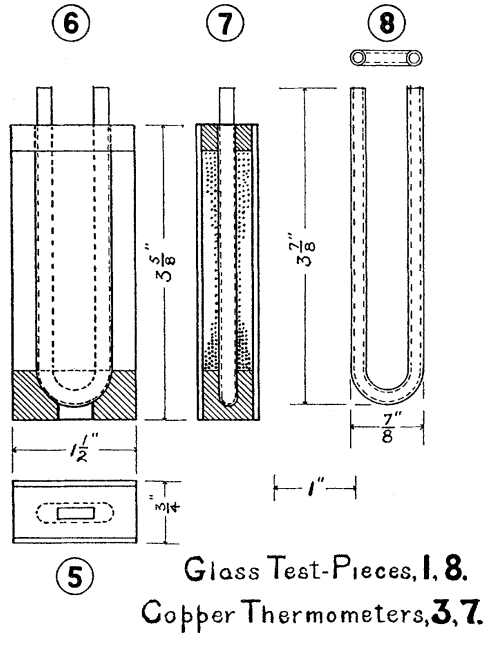

Fig. 1.

sistance of the specimen of amalgam, a Wheatstone bridge to determine the resistance of the copper thermometer.

Various materials were used to make the test-piece to contain the

${ }_{21}$ Bornemann and Müller, Metallurgie, г9го, 7, pp. 396-402.

${ }^{22}$ Bornemann and Rauschenplat, Metallurgie, I9I 2, 9, pp. 473-486, 505-5I 5 .

${ }^{23}$ Vanstone, The Chemical News, Vol. I08, No. 28 Io, p. I64. 
amalgam, such as paper fibre tubing, quartz tubing, and glass tubing. The final test-piece that was used, was made of U-shaped glass tubing, so fashioned as to slip into the copper thermometer as shown in (I) and (3) of Fig. I. A piece of glass tubing about $40 \mathrm{~cm}$. in length, an average inner diameter of $2.87 \mathrm{~mm}$. was used, this test-piece contained $29.7 \mathrm{I} 4$ grams of pure mercury at $18^{\circ} \mathrm{C}$; the approximate length of the inner bore was about $33 \mathrm{~cm}$. Later, in the work, it was thought best to make a smaller container for the specimen of the amalgam. A piece of glass tubing about $20 \mathrm{~cm}$. in length, an average inner diameter of $3.05 \mathrm{~mm}$. was used. This test-piece contained 19.98 grams of pure mercury at $18^{\circ} \mathrm{C}$.; the approximate length of the inner bore was about $\mathrm{I} 7 \mathrm{~cm}$., as shown in (6) and (8) of Fig. I.

These two test-pieces were calibrated throughout the range of temperature with the change of resistance of pure mercury. Care was taken each time to have the same amount of material by volume in the test-piece and the same conditions were maintained during each of the several runs.

\section{The Copper Thermometers.}

The different temperatures of the test-piece were measured by means of a copper thermometer, No. I. On a thin copper tube of internal diameter of $6 \mathrm{~mm}$. and length of $12 \mathrm{~cm}$. were wound several layers of No. 36 single silk covered copper wire through the length of $8 \mathrm{~cm}$. There was made a duplicate of the same, each having a resistance of about $44.2 \mathrm{I}$ ohms at room temperature of $2 \mathrm{I} .5^{\circ} \mathrm{C}$. These tubes were mounted in fibre supports as shown in (2), (3) and (4) of Fig. I, and the ends were soldered together, giving a resistance of about $88.4 \mathrm{I}$ ohms at room temperature. To the other ends of the copper wire were soldered three leads, two to one end and one to the other, each lead of a length of $300 \mathrm{~cm}$. These leads were made of No. 24 cotton covered wire and each had a resistance of $0.255 \mathrm{ohm}$ at $20^{\circ} \mathrm{C}$.

A smaller copper thermometer, No. 2, was made later by using several layers of No. 30 cotton covered wire which was wound on a form of thin sheet copper as shown in (5), (6) and (7) of Fig. I. The resistance of this thermometer including its lead wires in melting snow was 33.55 ohms. The lead wires were three in number, connected as in the previous thermometer No. I, made of No. 20 cotton covered wire, and each lead has a resistance of $0.145 \mathrm{ohm}$ at $20^{\circ} \mathrm{C}$.

The resistance of each thermometer was measured by a Wheatstone bridge, a special dial type made by Leeds and Northrup Co. The ratio coils of this bridge were Io to I,ooo, and a check of the bridge was made by a comparison with a Wolff standard resistance of ten ohms, and one of one ohm. 
As shown in the diagram of this bridge, Fig. 2, the resistance of the three lead wires, $A C_{1}, C C_{1}$, and $B B_{1}$, become a part of the bridge itself; it follows that these lead wires can be considered eliminated by the

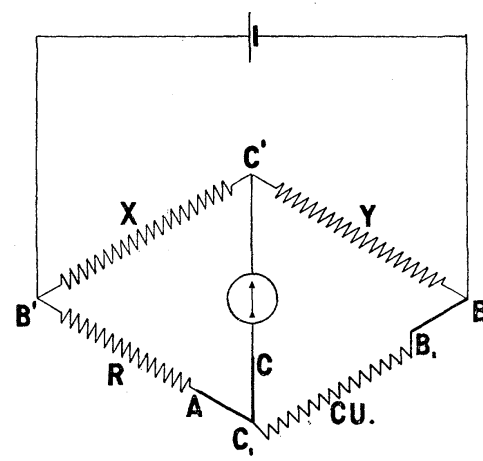

Fig. 2. bridge and any error in them, regarding resistance cha:nge, can be neglected. Various fixed points were determined carefully on both thermometers, by means of comparison with a standard thermo-junction, calibrated by the Bureau of Standards, at different temperatures. The equation for each thermometer was determined and was of the form $y=m x+b$.

Copper Thermometer No. I. - The resistance of this thermometer at the ice-

point was $8 \mathrm{I}$ ohms, and the following equation was used.

$$
R_{t}=8 \mathrm{I}+0.3463 t .
$$

A change of resistance in the thermometer of one tenth ohm was equal to a change in temperature of 0.28 of a Centigrade degree.

Copper Thermometer No. 2.-The resistance of this thermometer at the ice-point was $33.55 \mathrm{ohms}$, and the following equation was used.

$$
R_{t}=33.55+0.1468 t \text {. }
$$

A change of resistance in the thermometer of one tenth ohm was equal to a change in temperature of 0.68 of a Centigrade degree.

From the observed data, the following curves were plotted for Thermometer No. I and Thermometer No. 2, as shown in Fig. 3.

Arrangement of Apparatus.

The change of resistance of the specimen in the test-piece was measured directly by the Kelvin bridge. From the potential points on the bridge potential lead wires of equal resistance were carried to the specimen in the test-piece. The fall of potential in the specimen of amalgam was balanced by a like fall of potential in the standard low resistance of the bridge.

\section{Method of Observations.}

The test-piece, containing the specimen, having been properly connected with the current and potential lead wires to the Kelvin bridge, was immersed in a bath of petroleum ether in its copper container, the petroleum ether was constantly stirred by means of a jet of compressed air. The copper container was then placed in a large Dewar bulb con- 


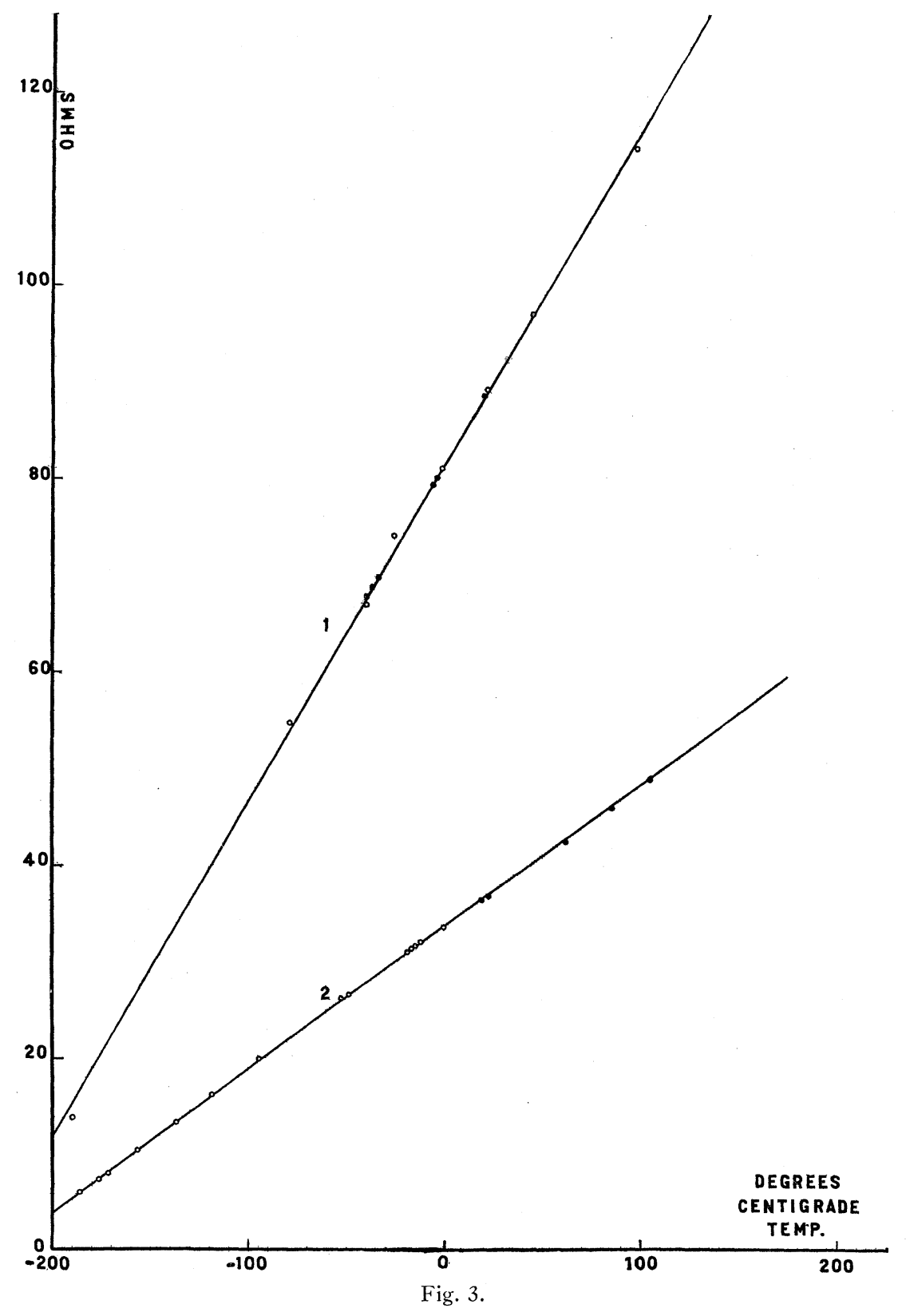

taining liquid air, and was gradually cooled to the low temperatures desired. When higher temperatures than room temperature were desired, the test-piece was immersed in a bath of petroleum oil free from any 
moisture, and heat was supplied by means of a current passing through a resistance coil wound around the copper container, the apparatus being placed in a Dewar bulb.

Referring to Fig. 4, $A$ represents the Dewar bulb; $B$, the space for liquid air; $C$, the copper container filled with petroleum ether; $D$, the

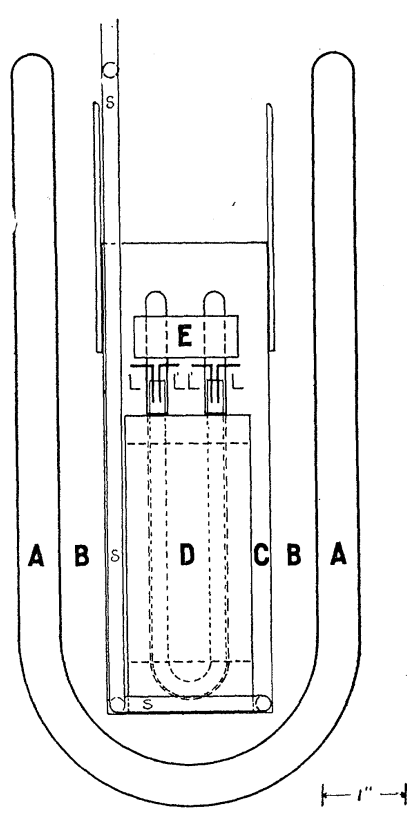

Fig. 4 . copper thermometer; $E$, the holder for the potential and current lead wires for the specimen; and $S$, the air stirrer immersed in petroleum ether.

The rate of cooling was slow and the temperature of the petroleum ether was assumed to be the same throughout its mass.

Readings were made on the Kelvin bridge at the same time the thermometer bridge indicated its balance. Readings of the resistance of the specimen were made by steps of one half ohm on the copper thermometer, and through the critical points, readings were made every one twentieth $\mathrm{ohm}$, the rate of cooling or warming was very slow. By this means very little temperature lag, if any, was noticed.

The Amalgams of Sodium.

Redistilled mercury and pure sodium furnished by Eimer and Amend were used in the preparation of the amalgams. Some paraffin wax was melted and freed from any moisture content; under it was placed a certain amount of pure mercury; by weight a certain amount from clean sodium was gradually added, the action was hastened by heating the whole mass in an evaporating dish. The amalgams were then poured into the cold petroleum ether, which dissolved the paraffin; later each amalgam was placed in separate containers and covered with petroleum ether until used.

Method of Analysis of the Amalgams.

The amalgams were analyzed by the titration method of the neutralization of a normal solution of hydrochloric acid by a normal solution of sodium hydroxide, phenophthalein was used as an indicator.

\section{REsUlts.}

In Figs. 5 to I4, the results of the investigation are shown graphically. In Figs. 5 to II, the values of the resistance of the amalgam, as ordinates, 
are plotted against the resistance of the copper thermometer and also directly in Centigrade degrees, as abscissæ. The temperature of the copper thermometer is expressed in ohms as well as in Centigrade degrees.

The freezing point of each amalgam is obtained from these curves thus plotted. It is assumed that freezing begins at the break of the curve in the liquid state and ends at the break of the curve in the solid state. The semi-frozen state is represented by that part of the curve approximately parallel to the ordinate axis. By taking the average of these points of temperature at the beginning and ending of this part of the curve, the average freezing point of the mercury in the particular amalgam

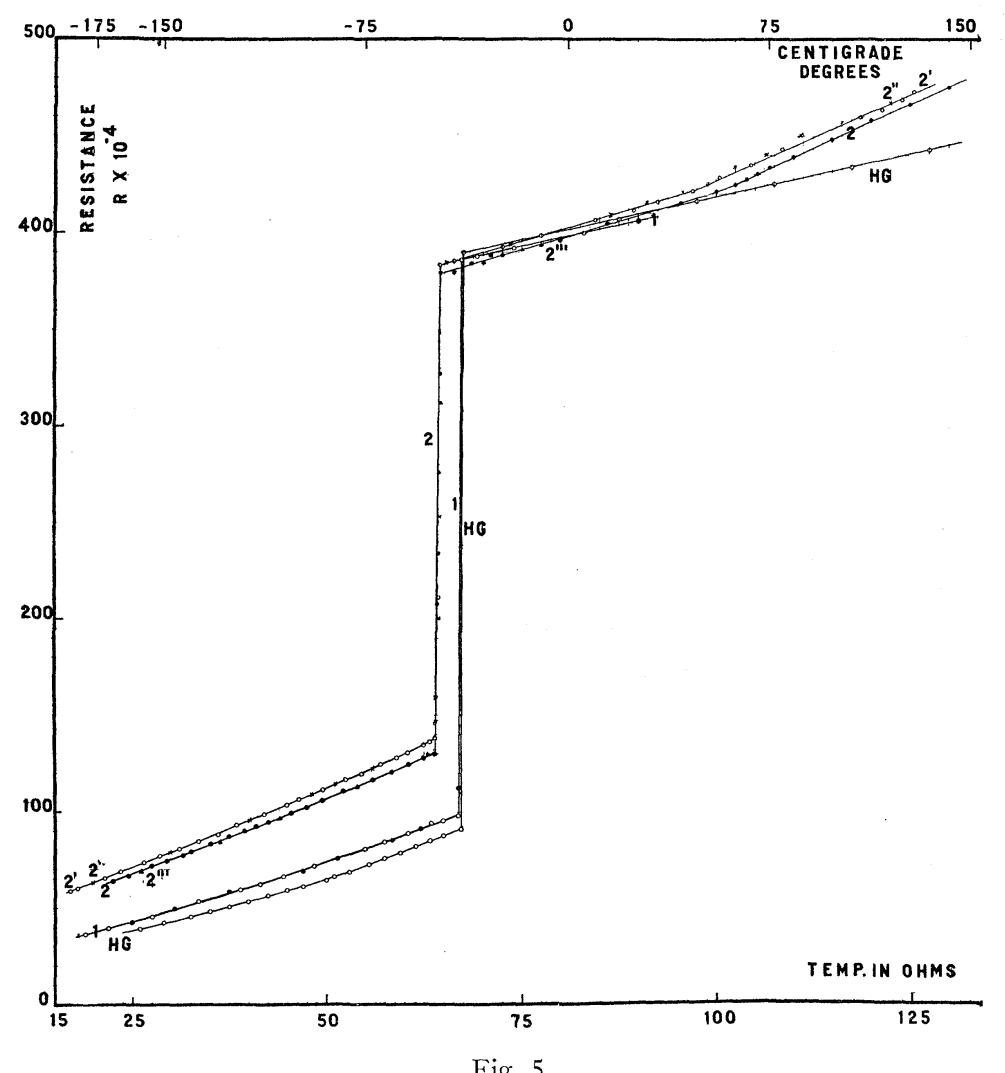

Fig. 5.

is found. These freezing points thus obtained are used in the plotted results as shown in Figs. $\mathrm{I} 2$ and $\mathrm{I} 3$.

In Fig. 5, the curve marked $H G$ is the calibration curve of the glass test-piece by the resistance change of mercury throughout the temperature change. Curve $I$ is for amalgam of sodium, showing a trace of 
sodium by analysis. Curves $2,2^{\prime}, 2^{\prime \prime}$, and $2^{\prime \prime \prime}$ of an amalgam of sodium, showing by analysis $0.65^{8}$ per cent. sodium by weight, or an atomic per cent. of 5.452 .

In the following discussion of the curves, each amalgam is numbered, the subscripts denote the number of heating runs above the room temperature of $20^{\circ} \mathrm{C}$., the superscripts denote the number of cooling runs below the room temperature. Throughout the discussion the room temperature mentioned refers to $20^{\circ} \mathrm{C}$.

Two runs were made on amalgam No. I for temperature resistance change from room temperature to that of liquid air; the second run being

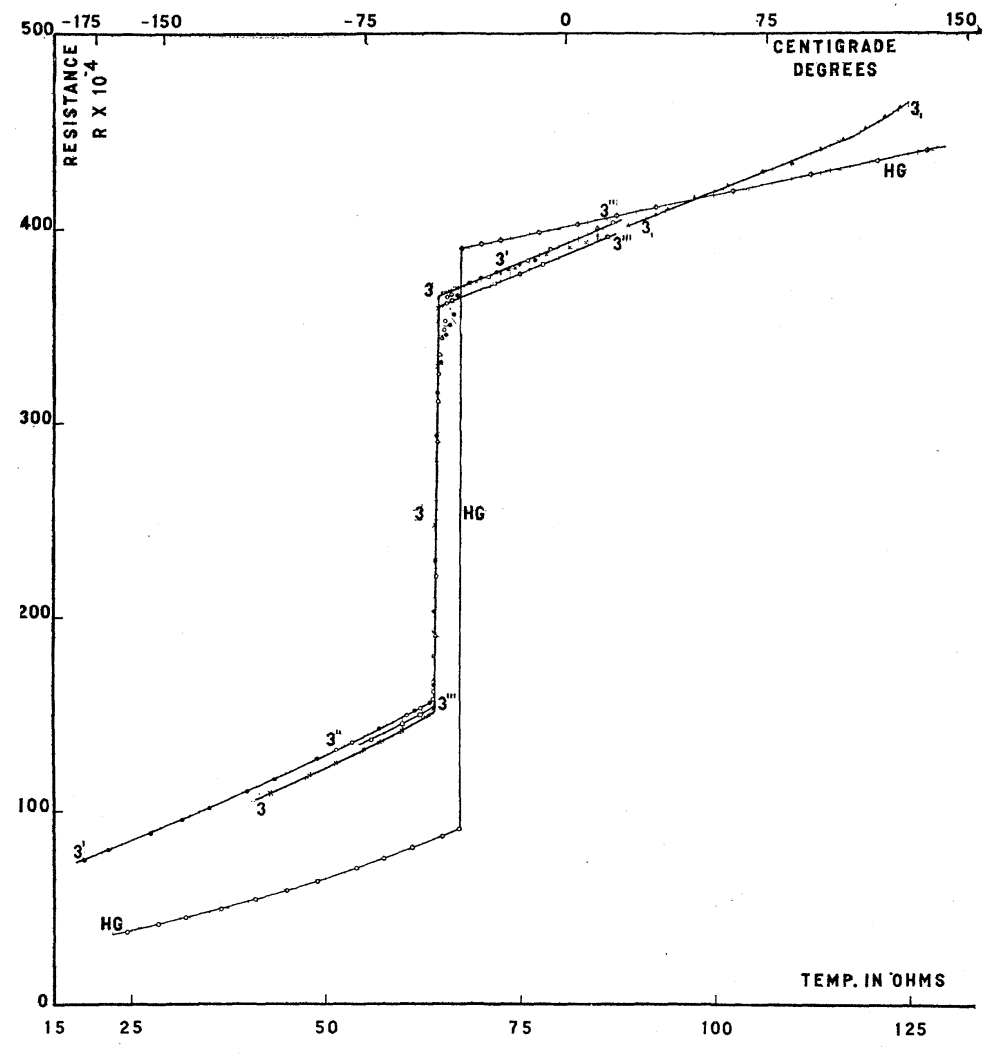

Fig. 6 .

a good check on the first run, as shown by the curve passing through the black circles and the black dots. The resistance of amalgam No. I being less than the liquid mercury, and greater than the solid mercury throughout the corresponding temperature changes.

Four runs were made on amalgam No. 2, all of them showing points 
on the freezing part of the curve, from the liquid to the solid state. Curves 2 and $2^{\prime \prime \prime}$ check throughout the range of temperature change, and the same is true of curves $2^{\prime}$ and $2^{\prime \prime}$, which, however, show a slight displacement above curves 2 and $2^{\prime \prime \prime}$; this may be explained because of the nature of the amalgam, which was liquid at room temperature, probably crystals of the compound $\mathrm{NaHg}_{4}$, long prismatic needles in shape, in the excess of mercury. There is a possibility of different arrangement of these crystals on freezing or melting of the sodium amalgam.

The same glass test-piece was used as the container for amalgam No. 3

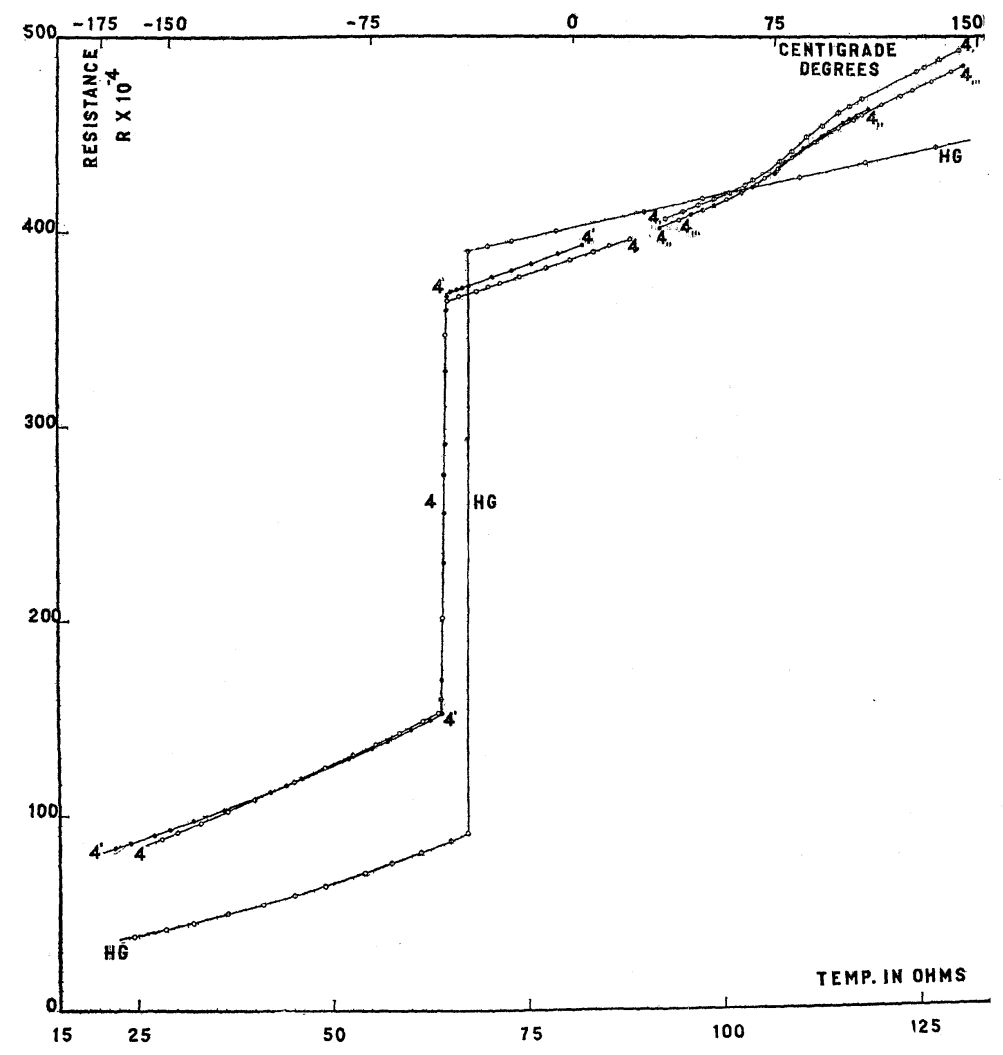

Fig. 7.

as was used in the previous runs. Analysis by weight showing 0.846 per cent. of sodium, the atomic per cent. of 6.93 of sodium, and long prismatic needles in liquid mercury at $20^{\circ} \mathrm{C}$.

Four runs were made on the temperature resistance change below room temperature, and one run above room temperature. The curves for the amalgam No. 3 through the change of state coincide, and are of 
the same general slope throughout the range of temperature change. The increase in percentage of sodium lowers the freezing point of the amalgam. The resistance of the solid amalgam No. 3 is greater than the resistance of the solid amalgam No. 2, as can be observed from a careful comparison of the two curves, Figs. 5 and 6 . These curves give the freezing point of amalgam No. I to be $-40.5^{\circ} \mathrm{C}$, for amalgam No. 2 to be $-47.93^{\circ} \mathrm{C}$., amalgam No. 3 to be $-48.64^{\circ} \mathrm{C}$., the freezing point of pure mercury to be $-38.80^{\circ} \mathrm{C}$.

The same glass test-piece was used as the container for amalgam No. 4 as was used in previous runs. Analysis by weight showing I.I74 per cent. sodium, the atomic per cent. of 9.387 , and prismatic needles in a

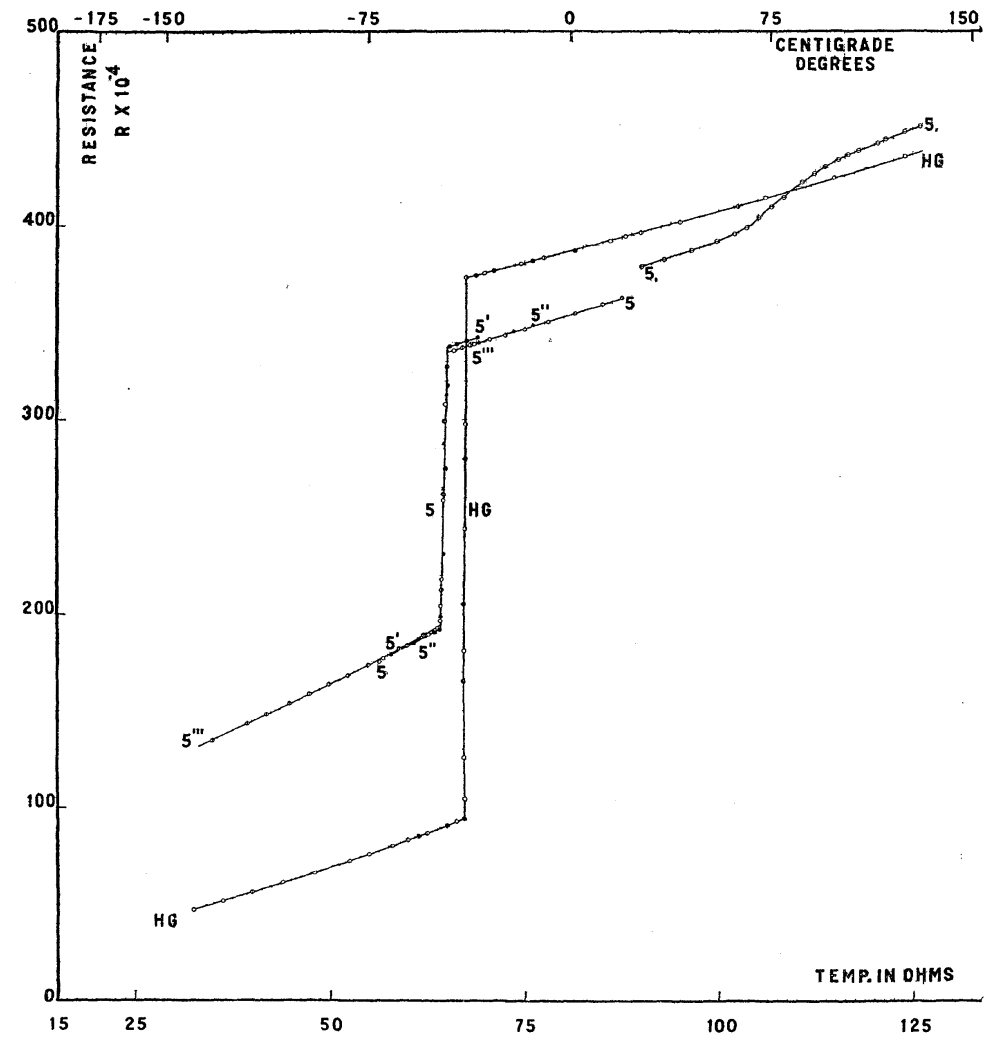

Fig. 8.

semi-pasty mass of the amalgam at $20^{\circ} \mathrm{C}$. The freezing point being $-48.43^{\circ} \mathrm{C}$.

Two runs were made on the temperature resistance change below room temperature and three runs for temperatures above, the plotted results 
being shown in Fig. 7. The curves for cooling runs coincide through the change of state, and show a higher resistance in the solid state for amalgam No. 4 than for amalgam No. 3 , a lower resistance in the semi-pasty state than for amalgam No. 3 .

The three runs made on the heating of the amalgam above room temperature all show a decided change in the slope of the curves in the neighborhood of the melting point of sodium, $97.5^{\circ} \mathrm{C}$, and it is possible that this change may be accounted for by the melting of the prismatic crystals in the amalgam.

A new glass test-piece of the same size was made to use as a container for amalgam No. 5, and was calibrated with mercury in the manner already described. The analysis of amalgam No. 5 shows 1.560 per cent.

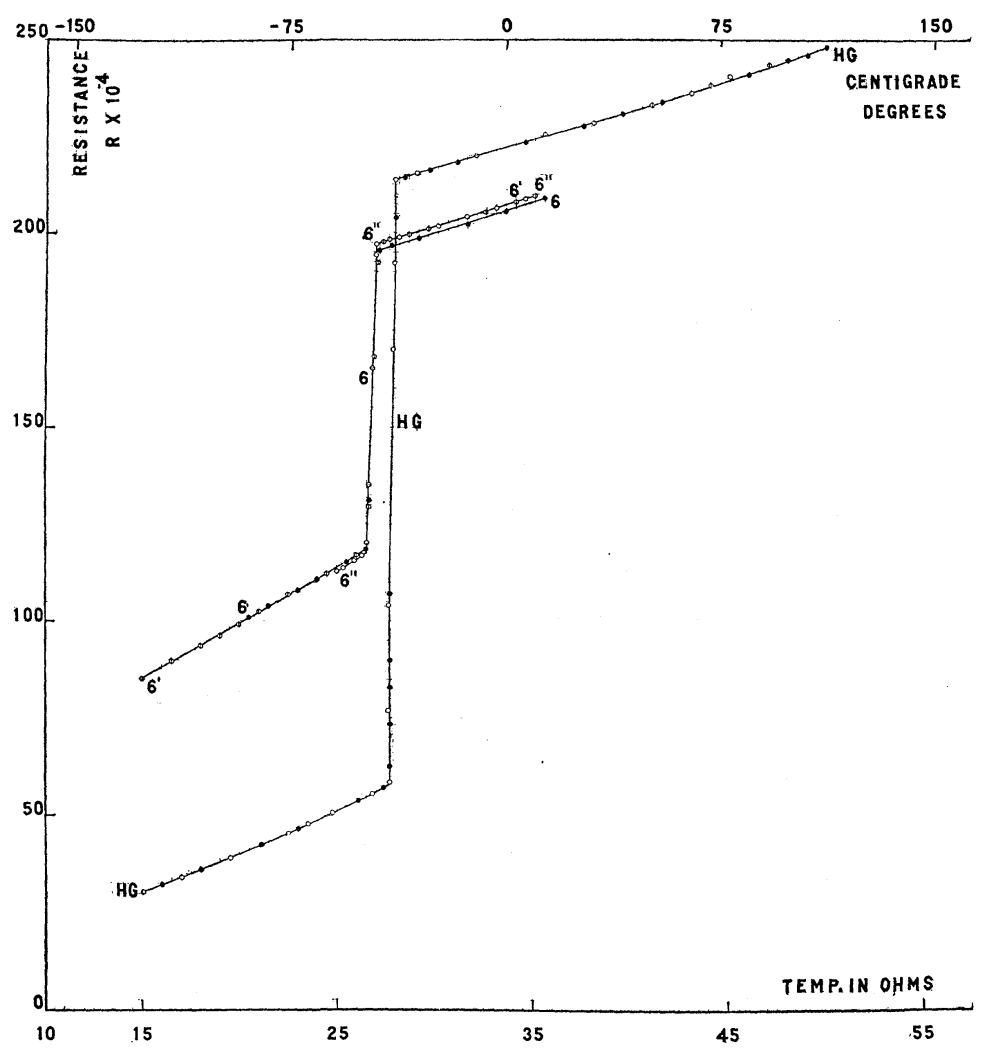

Fig. 9.

sodium by weight, or atomic per cent. of $12 . \mathrm{II}$; prismatic needle crystals in semi-pasty mass of the amalgam at $20^{\circ} \mathrm{C}$., freezing point of the amalgam being $-47.85^{\circ} \mathrm{C}$. 
Four runs were made on the temperature resistance change below room temperature and one above; the plotted results are shown in Fig. 8. The curves for cooling runs coincide throughout the change of state, the amalgam No. 5 shows a higher resistance in the solid state than for amalgam No. 4, a lower resistance in the semi-pasty state than for amalgam No. 4. There is the characteristic displacement of these curves; however, the slopes are the same, as already mentioned in the previous discussion of the other amalgams. The curve for the heating run shows a decided

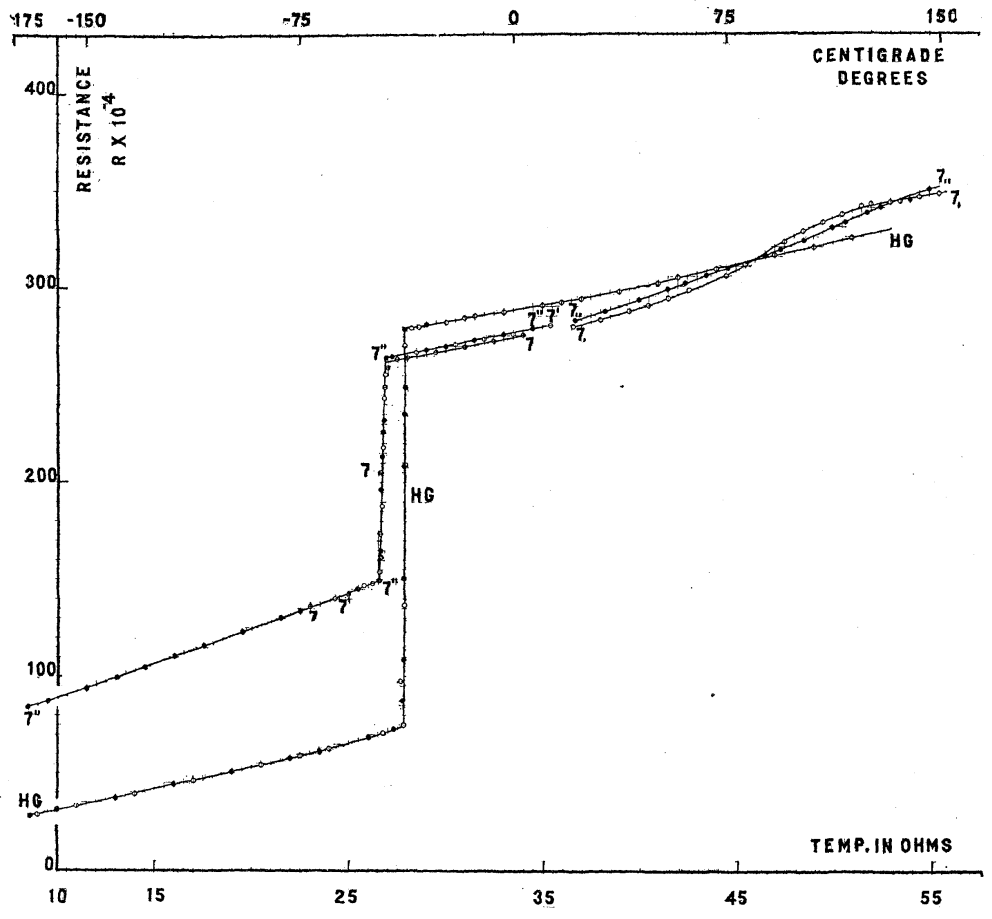

Fig. 10.

bend in the neighborhood of the melting point of sodium similar to the set of curves in the previous Figs. 5, 6, and 7 .

These curves already discussed were plotted from carefully inspected data, under the best conditions of a run; plenty of time was taken during the freezing of the amalgams, a great number of readings were made, and a few of these readings are shown as points on the different curves; especially during the change of state most of the points observed, were plotted.

A smaller glass test-piece for the amalgam and a new copper thermometer, more compact in size and shape as shown in Fig. I, was now used, 
with the hope that better results could be obtained. This test-piece was carefully calibrated by two runs with pure mercury throughout the range of temperature change in the same manner as already mentioned.

The analysis of amalgam No. 6 shows 2. Io per cent. sodium by weight, or atomic per cent. of 15.59 ; prismatic needle crystals in a soft-pasty mass of the amalgam at $20^{\circ} \mathrm{C}$., freezing point of the amalgam being $-47.52^{\circ} \mathrm{C}$.

Three runs were made on the temperature resistance change below room temperature, and then the glass test-piece was broken. Points on

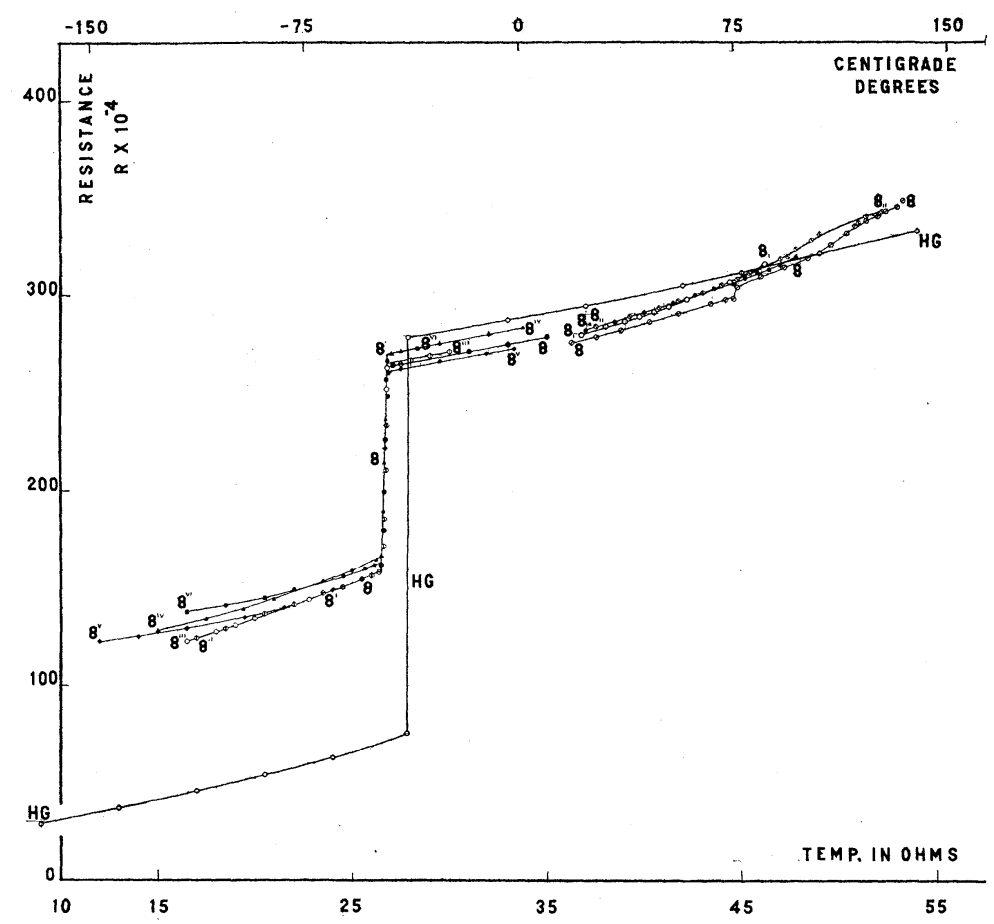

Fig. 11.

all three curves coincide through the change of state, the slopes of the three curves are the same in the soft-pasty state, and the curves show a slight displacement, which is possibly due to the arrangement of the crystals in the amalgam. The plotted results of these runs are shown in Fig. 9.

A new glass test-piece was made and used as a container for amalgam No. 7, which is the same as amalgam No. 6 by analysis.

Three runs were made on the temperature resistance change below room temperature, and two runs were made above, the plotted results are shown in Fig. Io. 
Points on all three curves coincide through the change of state, the slopes of the three curves are the same in the soft-pasty state, and again the curves show a slight displacement, as already discussed in previous curves. The two curves for the heating run above room temperature are of the same general shape; there is again evidence of the decided bend in the neizhborhood of the melting point of sodium.

TABLE I.

\begin{tabular}{c|c|c}
\hline \multicolumn{2}{c}{ Cooling Run on Amalgam No. 8, Below Room Temperature. } \\
\hline $\begin{array}{c}\text { Resistance in Ohms, } \\
\text { Copper Therm. }\end{array}$ & $\begin{array}{c}\text { Resistance in Ohms, } \\
\text { Amalgam No. 8. }\end{array}$ & \multicolumn{1}{|c}{ Remarks. } \\
\hline 35.00 & 0.027830 & $3: 45$ P.M. \\
33.00 & 0.027465 & \\
31.00 & 0.027100 & \\
30.00 & 0.026960 & Semi-solid state \\
28.90 & 0.026825 & \\
28.00 & 0.026630 & \\
27.50 & 0.026560 & \\
27.00 & 0.026450 & \\
& & \\
26.90 & 0.026150 & \\
26.80 & 0.025150 & \\
26.70 & 0.022650 & \\
26.50 & 0.018000 & Amalgam freezing \\
26.40 & 0.016200 & \\
& 0.016050 & \\
26.30 & 0.015900 & \\
26.20 & 0.015860 & Solid state \\
26.10 & 0.015800 & 5.35 P.M. \\
\hline
\end{tabular}

Part of a Cooling Run for Amalgam No. 8, from Room Temperature through the Change of State.

The same glass test-piece was used as a container for amalgam No. 8 as for amalgam No. 7. The analysis of amalgam No. 8 shows 2.67 per cent. sodium by weight, or atomic per cent. of I9.30; prismatic needle crystals in a semi-solid mass at $20^{\circ} \mathrm{C}$. Freezing point of the amalgam being $-47.25^{\circ} \mathrm{C}$.

Seven runs were made on the temperature resistance change below room temperature, and four runs were made above, the plotted results are shown in Fig. II.

Points on all seven curves coincide through the change of state, and these curves are in good agreement below the freezing point to the temperature of liquid air. Curves $8^{\mathrm{v}}$ and $8^{\mathrm{vI}}$ show a more decided curvature 
TABLE II.

\begin{tabular}{c|c|c}
\hline \multicolumn{2}{c}{ Heating Run on Amalgam No. 8, Above Room Temperature. } \\
\hline $\begin{array}{c}\text { Resistance in Ohms, } \\
\text { Copper Therm. }\end{array}$ & $\begin{array}{c}\text { Resistance in Ohms, } \\
\text { Amalgam No. 8. }\end{array}$ & Remarks. \\
\hline 37.00 & 0.027710 & $4: 00$ P.M. \\
38.00 & 0.027925 & \\
39.00 & 0.028215 & \\
40.00 & 0.028500 & \\
42.00 & 0.029050 & Semi-solid state of amalgam, which \\
44.00 & 0.029600 & on heating becomes liquid. \\
44.40 & 0.029660 & \\
44.60 & 0.029700 & \\
44.80 & 0.030300 & \\
45.20 & 0.030450 & \\
45.60 & 0.030715 & \\
46.00 & 0.030840 & \\
47.00 & 0.031250 & \\
48.00 & 0.031620 & \\
49.00 & 0.032150 & \\
50.00 & 0.032850 & \\
51.40 & 0.033710 & \\
52.00 & 0.033950 & \\
53.00 & 0.034415 & \\
\hline
\end{tabular}

Part of a Heating Run for Amalgam No. 8, from Room Temperature to about $135^{\circ} \mathrm{C}$.

at the lower temperatures than the others, this is possibly due to the arrangement of the crystals in the amalgam on freezing, or some temperature lag as the petroleum ether became thick and was difficult to thoroughly stir at that region of temperature. These curves also show the displacement which is characteristic of the amalgams already mentioned.

A comparison of Fig. I I with Fig. Io shows that the resistance of amalgam No. 8 in the solid state is higher than the resistance of amalgam No. 7 in the solid state; also the resistance of amalgam No. 8 is lower than the resistance of amalgam No. 7 in the semi-solid state between room temperature and the freezing point.

A careful study of the four heating runs above room temperature was made with the hope of determining a definite change in the shape of the curves at the region of the melting point of sodium. These curves all show the bend which is characteristic of the other amalgams, they are more or less displaced, the slopes are slightly different from those in the neighborhood of room temperature. No attempt was made to make a continuous run from liquid air temperature to the high temperatures on account of the length of time involved and the necessary change of the stirring bath of petroleum ether to that of petroleum. Plenty of time 
was used, however, the runs were in length from six to eight hours of continuous observations. Care was taken to obtain a slow rate of cooling through the freezing of each amalgam, and then checking runs were made under the same conditions. Throughout the whole investigation care was taken to assure repetitions of the conditions governing the different runs of the several amalgams.

From the data already obtained, a curve was plotted; the melting or freezing points of the amalgams as ordinates and the atomic percentage of sodium in the amalgam as abscissæ.

TABLE III.

\begin{tabular}{c|c|c|c|c|c|c}
\hline \multirow{2}{*}{ Specimen. } & \multicolumn{2}{|c|}{ Wt. \%. } & \multicolumn{2}{c|}{ Atomic \%. } & $\begin{array}{c}\text { Melting Pt. } \\
\text { Deg. C. }\end{array}$ & $\begin{array}{c}\text { Depression } \\
\text { Deg. C. }\end{array}$ \\
\cline { 2 - 6 } & Na. & Hg. & Na. & Hg. & & \\
\hline Hg. & 0 & 100 & 0 & 100 & -38.80 & 0.00 \\
1 & Trace & $99.9+$ & 1.05 & 98.950 & -40.50 & 1.70 \\
2 & 0.658 & 99.342 & 5.452 & 94.548 & -47.93 & 9.13 \\
3 & 0.846 & 99.154 & 6.930 & 93.070 & -48.64 & 9.84 \\
4 & 1.174 & 98.826 & 9.387 & 90.613 & -48.43 & 9.63 \\
5 & 1.560 & 98.440 & 12.110 & 87.890 & -47.85 & 9.05 \\
6 & 2.100 & 97.900 & 15.590 & 84.410 & -47.52 & 8.72 \\
8 & 2.670 & 97.330 & 19.306 & 80.694 & -47.25 & 8.45 \\
\hline
\end{tabular}

Referring to Fig. I2, the curve plotted shows an eutectic point in the region of $-48.75^{\circ} \mathrm{C}$., with an atomic per cent. of sodium in the amalgam of 5.90 , which is a higher value than that obtained by Vanstone.

TABLE IV.

\begin{tabular}{|c|c|c|c|c|c|c|c|}
\hline \multirow{2}{*}{ Specimen. } & \multicolumn{2}{|c|}{ Atomic Per Cent. } & \multicolumn{3}{|c|}{ Resistance in Ohms of Specimen. } & \multirow{2}{*}{$\begin{array}{l}\text { Per Cent. } \\
\text { Change. }\end{array}$} & \multirow{2}{*}{$\begin{array}{c}\text { Melting } \\
\text { Point. }\end{array}$} \\
\hline & $\mathrm{Na}$. & $\mathrm{Hg}$. & Liquid. & Solid. & Change. & & \\
\hline $\mathrm{Hg}$. & 0.00 & 100.00 & 0.03900 & 0.00910 & 0.02990 & 76.70 & -38.80 \\
\hline Amalgam 1. & 1.05 & 98.95 & 0.03860 & 0.00982 & 0.02878 & 74.50 & -40.50 \\
\hline 2 . & 5.452 & 94.548 & 0.03830 & 0.01380 & 0.02450 & 63.80 & -47.93 \\
\hline 3 . & 6.930 & 93.070 & 0.03670 & 0.01490 & 0.02180 & 59.60 & -48.64 \\
\hline 4. & 9.387 & 90.613 & 0.03642 & 0.01542 & 0.02100 & 57.70 & -48.43 \\
\hline $5 \ldots$ & 12.110 & 87.890 & 0.03375 & 0.01920 & 0.01455 & 43.15 & -47.85 \\
\hline 6. & 15.590 & 84.410 & 0.02612 & 0.01495 & 0.01117 & 42.55 & -47.52 \\
\hline 8. & 19.306 & 80.694 & 0.02660 & 0.01665 & 0.09950 & 37.40 & -47.25 \\
\hline
\end{tabular}

From the data already obtained, Table IV., a curve was plotted; the melting or freezing points of the amalgams as ordinates and the percentage change of resistance of the amalgam on freezing as abscissæ. Referring to Fig. I3, the curve plotted shows a sharp bend in the region of 


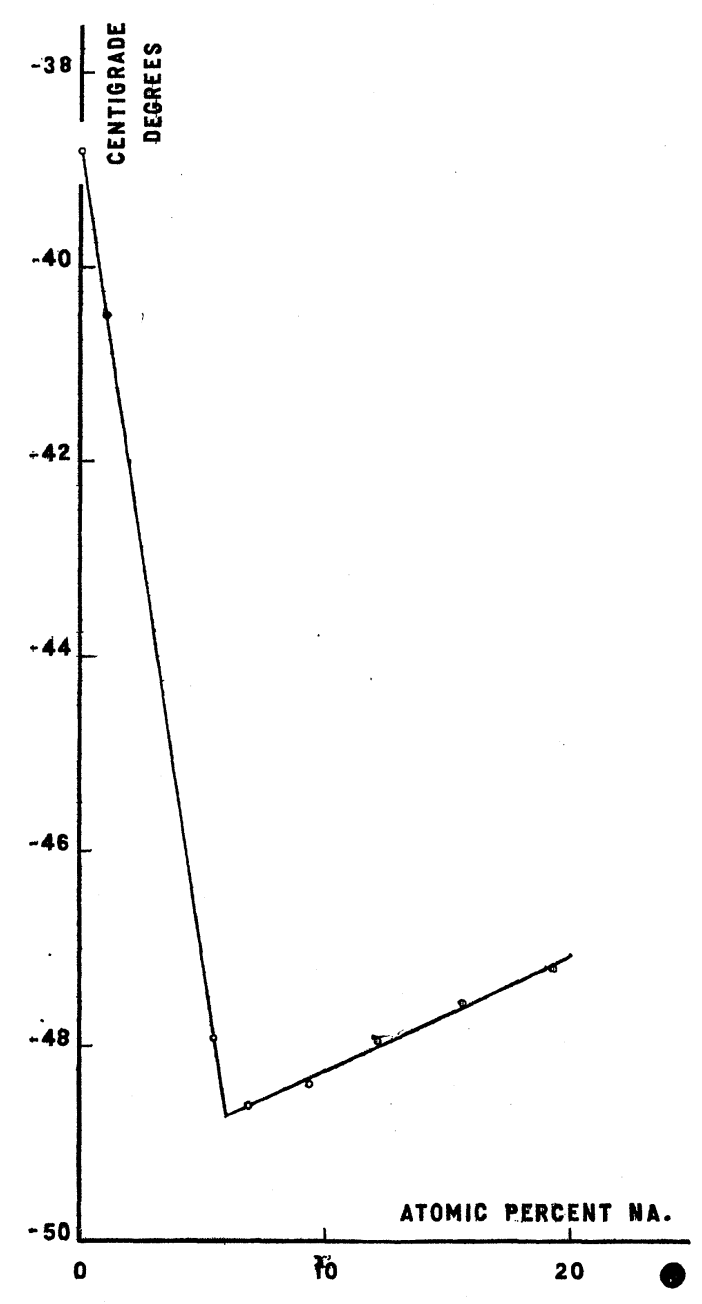

Fig. 12.

$-48.75^{\circ} \mathrm{C}$., with a percentage change in resistance on freezing of 64.4 ; it is interesting to note that this sharp bend in the curve coincides with the temperature of the eutectic point of the curve plotted in Fig. I2.

Another curve was plotted from the same data, using as ordinates the atomic percentage of sodium in the amalgam, and as abscissæ, the percentage change of the resistance of the amalgam on freezing.

The results are plotted as shown in Fig. I4; through six of the points a smooth curve can be drawn, the remaining two points probably are in error. 


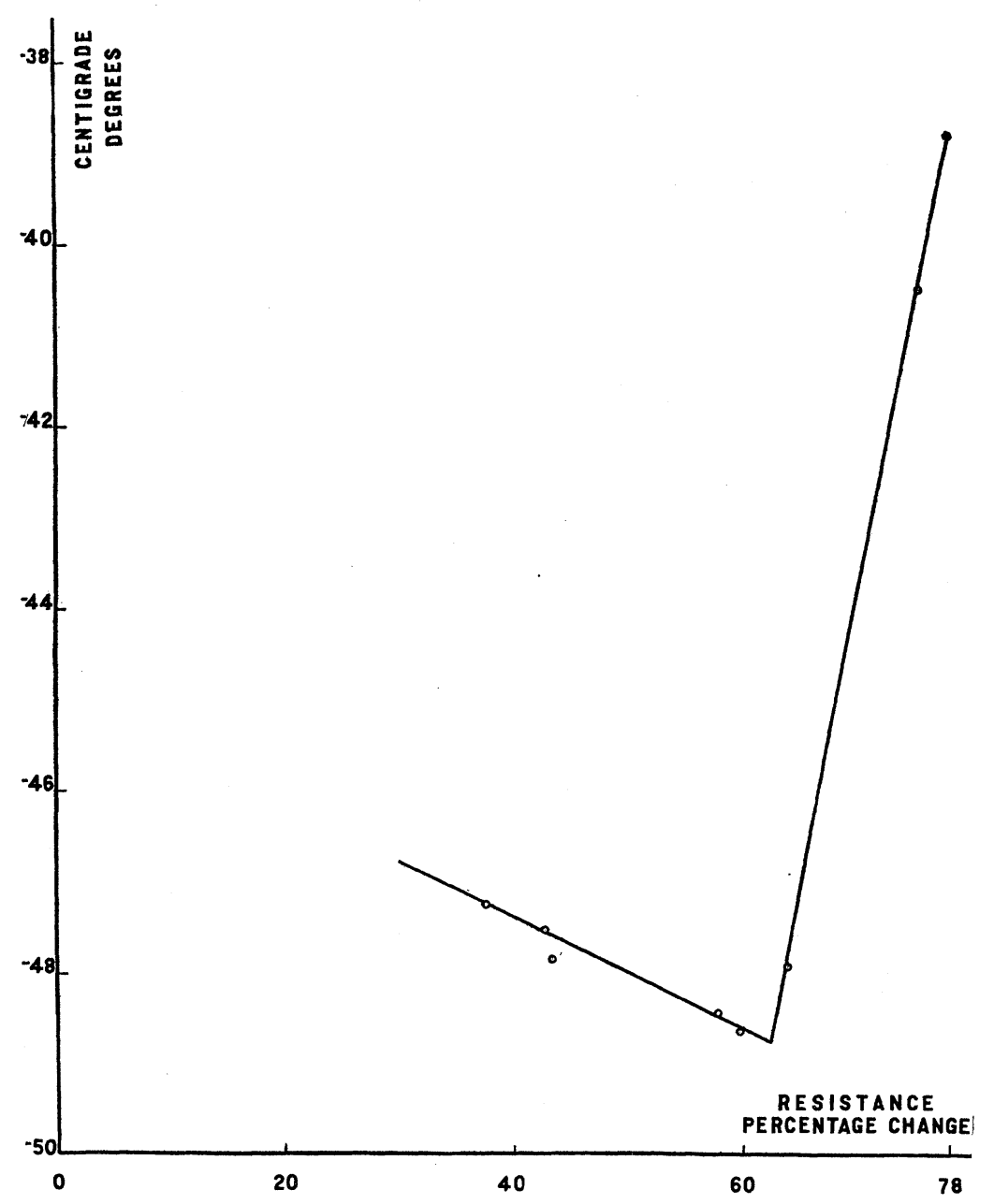

Fig. 13.

The work will be carried on in the near future, using amalgams of higher percentage of sodium.

The author wishes to acknowledge his indebtedness to Prof. E. L. Nichols, at whose suggestion the work was begun, to Prof. J. S. Shearer and Prof. Ernest Blaker who aided and encouraged the work. Valuable assistance has been received from Dr. R. C. Snowdon, Mr. C. C. Murdock and others. 


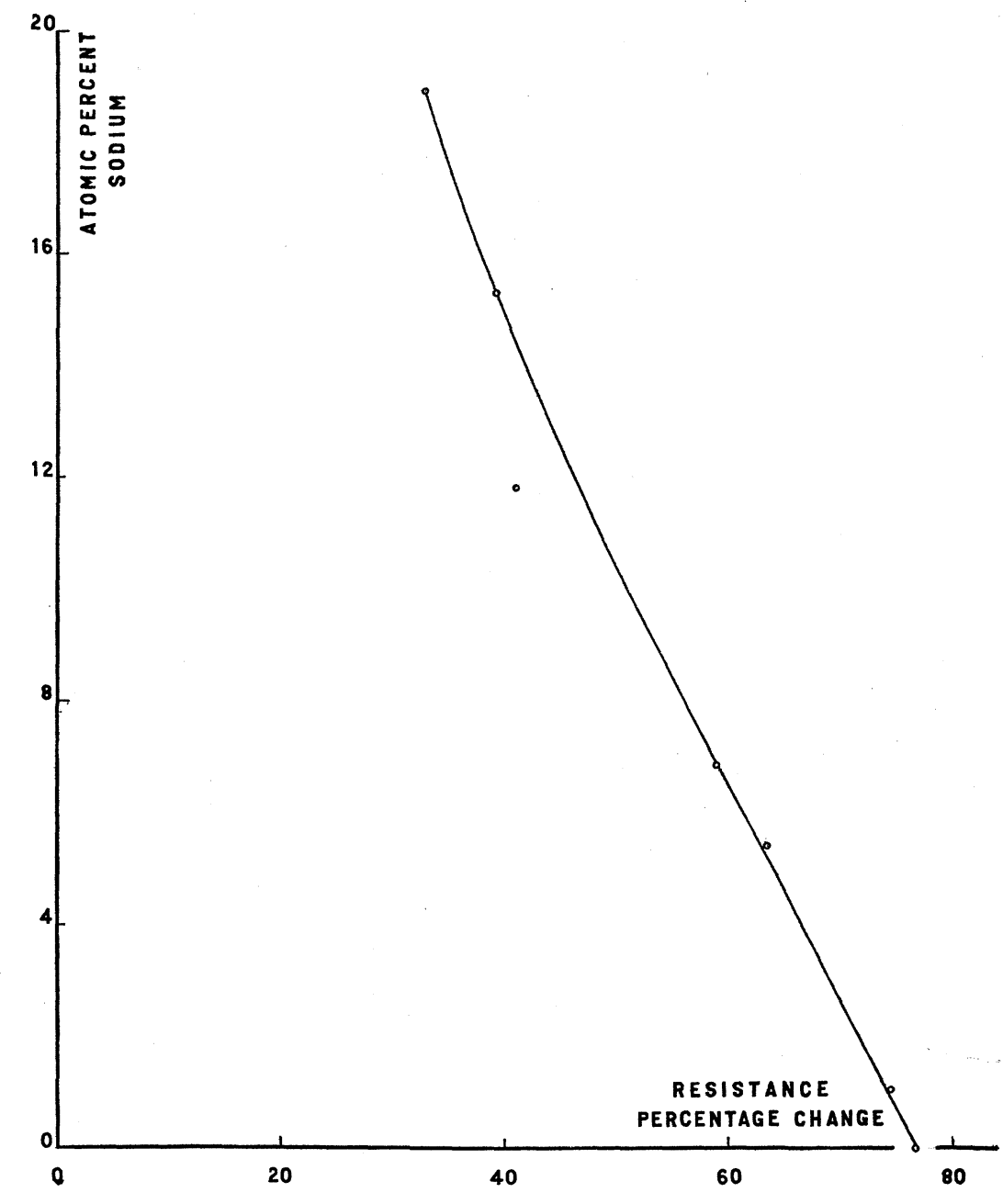

Fig. 14.

Rockefeller Hall, Cornell University, ITHACA, NEW YORK. 